Powell, J. F. (1951). J. gen. Microbiol. 5, 993-1000.

\title{
The Sporulation and Germination of a Strain of Bacillus megatherium
}

\author{
BY JOAN F. POWELL \\ Microbiological Research Department (Ministry of Supply), Porton, Wiltshire
}

SUMMARY: A strain of Bacillus megatherium has been isolated which requires glucose specifically for optimal spore germination. Cyanide, fluoride, iodoacetate, citrate, oxalate, azide, and 2:4-dinitrophenol were ineffective as inhibitors of germination in glucose, while 8-hydroxyquinoline inhibited completely at $10 \mathrm{~mm}$. The inhibitory effect of glucose on sporulation of the organism in liquid and solid media is described.

It has been found (Hills, 1949 $a$ ) that a simple medium containing L-alanine, tyrosine, and adenosine provides practically optimal conditions for germination of certain strains of Bacillus anthracis. The germination of a laboratory strain of $\boldsymbol{B}$. subtilis in a buffered medium containing L-alanine only has also been described (Hills, 1950; Powell, 1950). An attempt is now being made to discover the germination requirements of other sporing bacteria; the criterion of germination is again taken as loss of heat resistance, accompanied by change in staining properties and refractivity. In the present report, the sporulation and germination of a strain of $B$. megatherium freshly isolated from air are described. The spores of this organism have been found to require glucose specifically for optimal germination, which proceeds to 80-90\% completion in 30 min. at $35^{\circ}$ at spore concentrations up to $2.5 \times 10^{9} / \mathrm{ml}$.

A complete systematic investigation of the factors affecting sporulation of this organism has not been made. The effect of adding excess glucose to the medium with and without aeration has been observed, but, as Knaysi (1945 $a$ ) points out, the factors affecting sporulation are complex and interrelated, so that these observations must be regarded as incomplete.

\section{METHODS}

\section{Sporulation}

It was found difficult at first to obtain suspensions consisting entirely of viable spores. On CCY agar (Gladstone \& Fildes, 1940) few spores were formed in 3 days; after incubation for approximately 7 days, CCY cultures produced many spores, but $80 \%$ of these stained densely by the carbol fuchsinmethylene blue technique (Pl. 1, fig. 1) (Powell, 1950) and could be shown, by a comparison of the direct chamber count with the plate count, to be nonviable. The addition of $10 \mathrm{~mm}$. oxalate to the CCY agar medium (Bordet \& Renaux, 1930) induced practically complete sporulation in 2 days, but there were still c. $20 \%$ of densely staining forms. The first experiments on germination requirements were done using suspensions of this type, after five washings with distilled water. 
The meat extract peptone agar medium used by Tarr (1933) for spore production was later found to be much more satisfactory, giving suspensions containing less than $5 \%$ of densely staining non-viable forms (Pl. 1, fig. 2). Growth on this medium was, however, rather poor, although somewhat improved by the addition of small concentrations (5-8 $\mathrm{mm}$.) of glucose (see below). Spores were reaped after 2 days' incubation at $37^{\circ}$, and washed five times with distilled water before use.

\section{Germination}

Germination was studied at a spore count of $10^{8}$ to $10^{9} / \mathrm{ml}$. and was usually assessed by determining the percentage of spores which became densely staining (carbol fuchsin and methylene blue) during the experiment. This figure for percentage germination agreed with the proportion of spores which had lost their heat resistance as determined by the viable count before and after heating at $60^{\circ}$ for $15 \mathrm{~min}$. (Hills, 1949b). In some experiments, germination was followed by measurements of turbidity, percentage transmission being determined at $610 \mathrm{~m} \mu$. in a Coleman spectrophotometer. The E.E.L. nephelometer (Evans Electro Selenium) was also used and found to be rather more sensitive. In this instrument, a test-tube containing the turbid suspension, illuminated from below, is surrounded by photocells which receive the scattered light. During germination, light scattering and refractivity of the spore are considerably diminished and the instrument readings decrease.

The results which follow suggest that densely staining non-viable spores are produced as a result of growth on media which, although too exhausted or too toxic to permit further growth, still contain an excess of the substances which stimulate germination. It seems that the process involving loss of heat resistance is not directly reversible under these conditions. In this connexion, it has been found desirable with this organism to cool suspensions at $0^{\circ}$ as they are reaped and until they have been washed several times. When on one occasion an incompletely washed spore suspension was inadvertently allowed to stand at room temperature for 4-5 hr., it was found to have germinated almost completely.

\section{RESULTS}

Germination

It was found that after $30 \mathrm{~min}$. incubation of a $10^{9} / \mathrm{ml}$. spore suspension (grown on Tarr medium) in 5 mM. glucose buffered with 33 mM. phosphate pH $7 \cdot 3$, $80-90 \%$ of the cells had become densely staining (Pl. 1, fig. 3). In five experiments, percentage germination was determined in the same sample by both the staining and plating techniques. Agreement between the two methods was satisfactory (Table 1) and it was also found that the germinated cells retained their viability on further incubation for $1 \mathrm{hr}$. Phosphate, tested in the $\mathrm{pH}$ range $6-8$, was not stimulatory; germination proceeded equally well in unbuffered glucose, or in glucose buffered with acetate at $\mathrm{pH} \theta$ or bicarbonate at pH 8. Glucose solutions were generally autoclaved before use: since Seitz filtered solutions gave exactly similar results, the stimulatory effect of 
glucose cannot be ascribed to products formed during autoclaving (cf. Emerson, 1948).

Freshly harvested spore suspensions usually germinated satisfactorily in buffered glucose. In a few cases, possibly because of uncontrollable factors in the peptone growth medium, germination did not exceed 50-60\%, even after 14 days' storage of the original suspension at room temperature (cf. Powell, 1950). These suspensions, however, invariably gave at least $90 \%$ germination after they had been heated at $60^{\circ}$ for $30 \mathrm{~min}$., and this heat activation was retained indefinitely.

Table 1. Percentage germination in five samples measured by filming and plating

Film count

$\begin{array}{cc}\begin{array}{c}\text { Germination } \\ (\%)\end{array} & (\text { Total/germinated) } \\ \mathbf{8 8} & (\mathbf{3 0 6 , 2 6 9 )} \\ \mathbf{5 9} & (512, \mathbf{3 0 3 )} \\ \mathbf{7 0} & (\mathbf{5 2 1}, \mathbf{3 6 7}) \\ \mathbf{7 9} & (\mathbf{5 7 3 , 4 5 0 )} \\ \mathbf{7 7} & (\mathbf{5 9 2 , 4 5 3 )}\end{array}$

Plate count

$\begin{array}{cc}\begin{array}{c}\text { Germination } \\ (\%)\end{array} & (\text { Total/germinated) } \\ 90 & (\mathbf{8 8 2 , 7 9 2 )} \\ 69 & (\mathbf{7 5 9}, \mathbf{5 2 5}) \\ 68 & (\mathbf{7 3 8}, \mathbf{5 0 4 )} \\ 76 & (601,459) \\ 74 & (601,447)\end{array}$

Using the spore preparations grown on CCY-oxalate and containing at least $20 \%$ densely staining forms, $50 \mathrm{~mm}$. of either pyruvate, lactate, glycerophosphate or ribose, although they were considerably less effective, produced a result similar to that of glucose. All gave 20-30\% germination in $30 \mathrm{~min}$., and this was not increased by further incubation. When spore suspensions from Tarr medium became available containing less than $5 \%$ of nonviable forms, the stimulatory effect of these compounds was re-tested, and that of other carbohydrates determined. Ribose, glycerophosphate, lactate, and pyruvate were practically ineffective at $70 \mathrm{~mm}$. with these suspensions. Five mм. fructose gave $\mathbf{3 0} \%$ germination in $\mathbf{3 0} \mathrm{min}$., and $\mathbf{5 0} \mathrm{mm}$. fructose $\mathbf{7 5} \%$ in $30 \mathrm{~min}$. Maltose, sucrose, and galactose had no effect at 5 mM., but gave $20 \%$ germination at $50 \mathrm{~mm}$. It seems likely that the effectiveness of fructose at $50 \mathrm{~mm}$. may have been at least partly due to traces of glucose present as an impurity.

The rate of germination in buffered $5 \mathrm{~mm}$. glucose was compared with that in tryptic meat digest, by the turbidity method (Fig. 1). The rate of increase in percentage transmission in glucose was at least as great as, and possibly rather greater than, that in the complex medium. It appears very probable, therefore, that the presence of glucose provides optimum conditions for germination.

The effect of lowered temperature on the rate of germination is shown in Fig. 2. The decrease in light scattering proceeds more slowly at the lower temperature.

Various reagents known to be inhibitors of a stage of respiration or glycolysis have been tested as inhibitors of germination in glucose. In these experiments, the spores were first incubated in buffer for $30 \mathrm{~min}$. with the test substance 


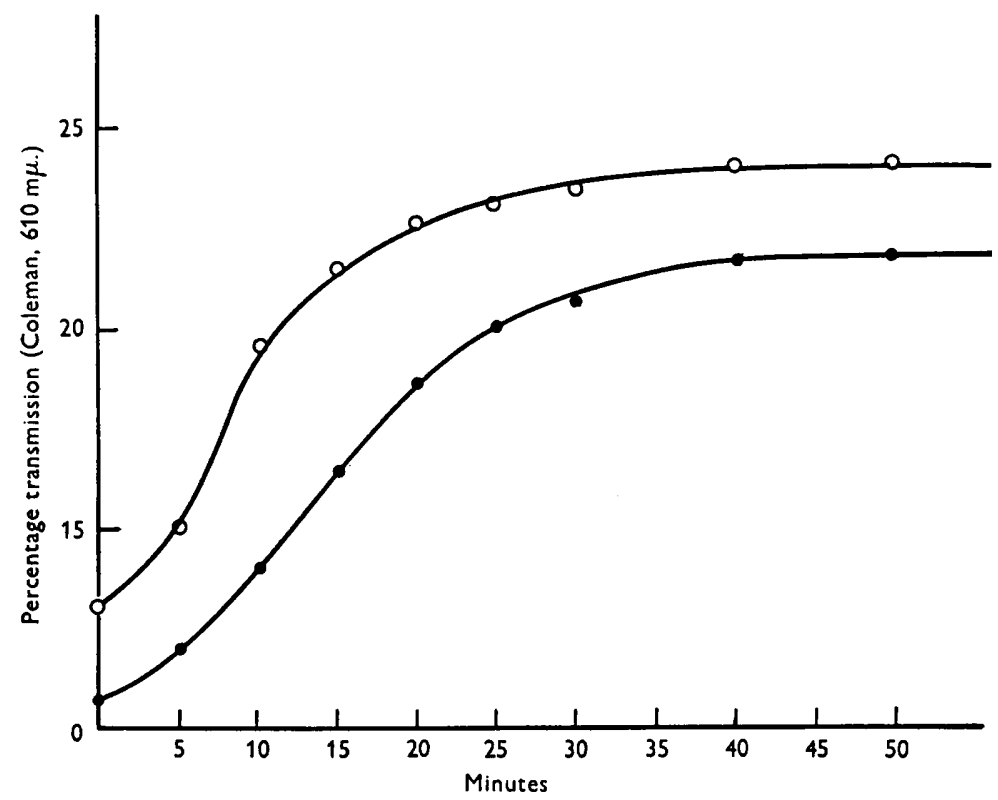

Fig. 1. The germination of $B$. megatherium at $37^{\circ}$ in $33 \mathrm{~mm}$. phosphate, $5 \mathrm{~mm}$. glucose $(\mathrm{O}-\mathrm{O})$ and in tryptic meat digest transmission made at $610 \mathrm{~m} \mu$.

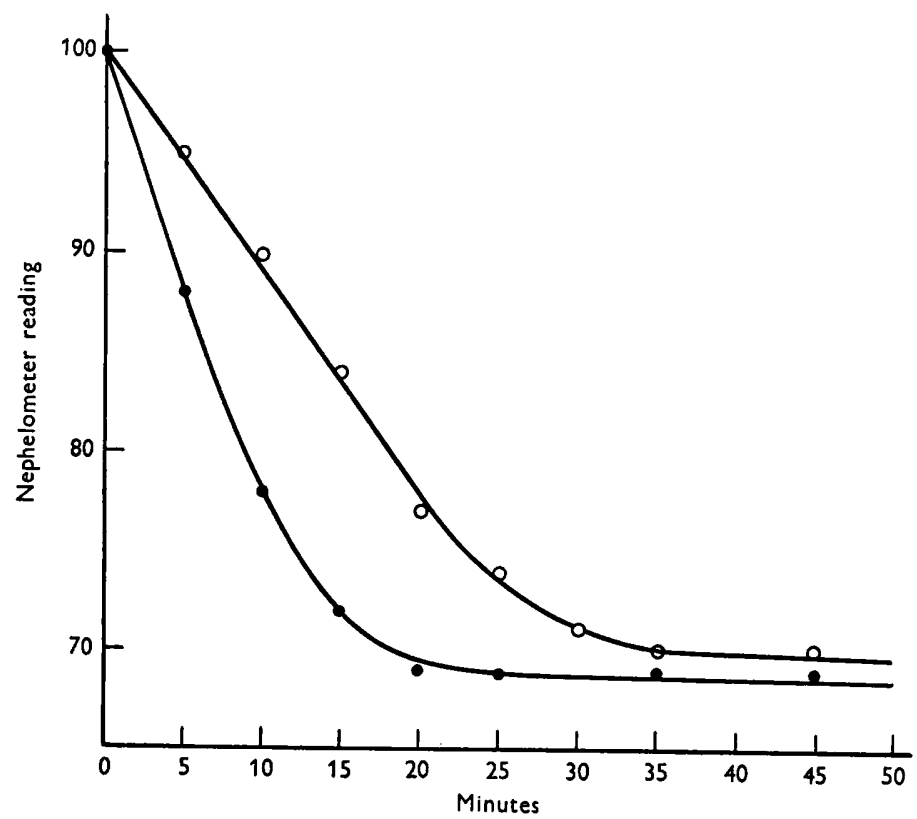

Fig. 2. The germination of $B$. megatherium in $33 \mathrm{~mm}$. phosphate, 5 mu. glucose at $24^{\circ}$ $(\mathrm{O} \bigcirc)$ and $37^{\circ}(-)$. Measurements of light scattering made in E.E.L. nephelometer. 
before glucose was added. One mm. cyanide, 5 mm. azide, 5 mm. 2:4-dinitrophenol, $10 \mathrm{~mm}$. fluoride, $10 \mathrm{~mm}$. iodoacetate, $30 \mathrm{~mm}$. oxalate, and $100 \mathrm{~mm}$. citrate were without effect. On the other hand, as with $B$. subtilis (Powell, 1950), 8-hydroxyquinoline (oxine) was strongly inhibitory, suppressing germination completely at $10 \mathrm{~mm}$., the isomeric 2-hydroxyquinoline being quite ineffective.

To compare the respiration of resting and germinated $B$. megatherium spores, Warburg manometers were used to measure oxygen uptake at $35^{\circ}$ in phosphate buffer before and after the addition of glucose to $10 \mathrm{~mm}$. There is a sudden and rapid uptake of oxygen beginning 15-20 min. after the addition of glucose. In a typical experiment, $2 \times 10^{9}$ spores suspended in $40 \mathrm{~mm}$. phosphate buffer $\mathrm{pH} 7 \cdot 3$ took up less than $10 \mu \mathrm{l}$. of oxygen in an hour, but $30 \mathrm{~min}$. after the addition of $10 \mathrm{~mm}$. glucose, a steady oxygen uptake of $50 \mu \mathrm{l}$. in $10 \mathrm{~min}$. was recorded.

\section{Sporulation}

In the early experiments, described above, it was found that the germination of spores harvested from CCY-oxalate was stimulated, to some extent, by glycerophosphate, pyruvate or lactate. It was expected, therefore, that sporulation might be increased on CCY medium by the omission of glycerophosphate, and decreased on Tarr medium by the addition of glycerophosphate, pyruvate, lactate, or glucose. This was found to be the case. On CCY agar without glycerophosphate, $50 \%$ sporulation occurred in 2 days, although half the spores were densely staining. The addition of sodium lactate (10 mu.) to the Tarr medium decreased sporulation considerably, and gave a high proportion of densely staining forms. There was slight inhibition of sporulation with $100 \mathrm{~mm}$. glycerophosphate. The most marked effect of adding glucose to the Tarr medium was to increase growth. At concentrations of 6 and $12 \mathrm{~mm}$. the addition did not reduce the tendency to sporulation-in fact, sporulation was generally better in these cultures than in the controls. Addition of $25 \mathrm{~mm}$. glucose, however, produced mainly non-sporing cells containing two or more small densely staining bodies. Some spores were produced, but, when free, mostly appeared as densely staining forms. The addition of $50 \mathrm{~mm}$. glucose had a similar, but more pronounced, effect. Pl. 1, fig. 4, shows a typical culture on Tarr medium and Pl. 1, fig. 5, a culture on Tarr medium to which $25 \mathrm{~mm}$. glucose was added; both cultures were examined after $24 \mathrm{hr}$. incubation at $35^{\circ}$.

As it is generally agreed that the minimum oxygen concentration required for sporulation is higher than that for growth (Knaysi, 1945a), the above results might therefore be explained on the basis that heavier growth in the presence of glucose produced 'overcrowding' and consequently oxygen shortage. Another effect of glucose in static culture will be to increase the acidity of the medium, perhaps to a point where sporulation is impossible. It was therefore desirable to compare the behaviour of the organism in shaken (i.e. aerated) culture with and without the addition of glucose. In these experiments, the Tarr medium was used, without agar, and the effect of glucose additions up to $50 \mathrm{~mm}$. was observed. Quadruplicate $50 \mathrm{ml}$. flasks containing $10 \mathrm{ml}$. of medium were set up at each concentration, giving duplicate 
flasks for shaken and static culture. The cultures were examined after 3 days' growth at $35^{\circ}$. In the absence of glucose, sporulation was good in shaken culture, but negligible when the culture was static. Although aeration and addition of glucose improved growth, it was found that glucose was inhibitory to sporulation at concentrations greater than $12 \mathrm{~mm}$. whether the cultures were $(a)$ aerated and maintained slightly alkaline at $\mathrm{pH} 8$, or $(b)$ static and allowed to become as acid as pH 5. The addition of $6 \mathrm{mM}$. glucose to shaken cultures did not diminish sporulation, but all the spores formed stained densely. On plating out, less than $1 \%$ of these densely staining spores were found to be viable. The results obtained are summarized in Table 2.

Table 2. Sporulation of Bacillus megatherium after 3 days at $35^{\circ}$ in meat extract peptone medium

\begin{tabular}{|c|c|c|c|c|}
\hline \multirow{2}{*}{$\begin{array}{l}\text { Glucose } \\
\text { concentration } \\
\text { (mM.) }\end{array}$} & \multicolumn{2}{|r|}{ Static cultures } & \multicolumn{2}{|r|}{ Shaken cultures } \\
\hline & $\mathbf{p H}$ & Sporulation & pH & Sporulation \\
\hline $\mathbf{0}$ & $\begin{array}{l}8 \cdot 0 \\
8 \cdot 1\end{array}$ & No spores seen & $\begin{array}{l}8 \cdot 1 \\
8 \cdot 1\end{array}$ & $\begin{array}{l}\text { Almost complete sporulation, } \\
\text { but many }(60 \%) \text { densely } \\
\text { staining forms }\end{array}$ \\
\hline 6 & $\begin{array}{l}8 \cdot 0 \\
7 \cdot 9\end{array}$ & $\begin{array}{l}\text { Very granular vegetative } \\
\text { cells }\end{array}$ & $\begin{array}{l}8 \cdot 2 \\
8 \cdot 2\end{array}$ & $\begin{array}{l}\text { Complete sporulation and all } \\
\text { spores densely staining }\end{array}$ \\
\hline 12 & $\left.\begin{array}{l}5 \cdot 7 \\
5 \cdot 6\end{array}\right)$ & No spores. Growth heavier. & $\begin{array}{l}8 \cdot 1 \\
8 \cdot 1\end{array}$ & $\begin{array}{l}\text { Poor sporulation. } \\
\text { Many granular vegetative cells }\end{array}$ \\
\hline 25 & $\begin{array}{l}\mathbf{5} \cdot \mathbf{2} \\
\mathbf{5} \cdot \mathbf{3}\end{array}$ & $\begin{array}{l}\text { Vegetative cells less } \\
\text { granular with increasing }\end{array}$ & $\left.\begin{array}{l}8 \cdot 0 \\
8 \cdot 2\end{array}\right\}$ & No spores. \\
\hline 50 & $\begin{array}{l}5 \cdot 2 \\
5 \cdot 2\end{array}$ & glucose concentration & $\left.\begin{array}{l}8 \cdot 1 \\
8 \cdot 1\end{array}\right\}$ & All granular vegetative cells \\
\hline
\end{tabular}

Better sporulation was obtained on CCY agar by adding oxalate than by omitting glycerophosphate. It is possible that here another factor is operating: namely, the concentration of available calcium (Bordet \& Renaux, 1930). If this is so, sporulation might be expected to increase on the CCY medium on addition of citrate, and to decrease on the Tarr medium on addition of soluble calcium salts. However, it was found that the addition of sodium citrate up to $20 \mathrm{~mm}$. to the CCY medium did not improve sporulation; neither did the addition of calcium chloride up to $13 \mathrm{~mm} .(0.5 \mathrm{mg}$. Ca/ml.) to the Tarr medium reduce sporulation. It appears probable, therefore, that the improved sporulation observed on adding sodium oxalate to the CCY medium is due to an effect of the oxalate ion per se.

\section{DISCUSSION}

Using a microscopic technique, Knaysi $(1945 b)$ found that germination of $B$. mycoides is stimulated by phosphate buffered glucose. Although no preliminary heat treatment was given, it seems likely that conditions in these experiments were not optimal for the organism tested, since only $30 \%$ germination occurred in $5 \mathrm{hr}$. Spores of the freshly isolated strain of $B$. megatherium used in the present work require only glucose as an external stimulant for optimal germination. It is possible that the preliminary heat activation required by some spores produces an internal stimulant (Goddard, 1939), the 
initial concentration of which is regulated by so far uncontrollable factors in the growth medium. Alternatively, it may be suggested that heating facilitates the excretion by the spore of substances which antagonize its germination, the concentration of these substances initially present depending on growth conditions. It has been found recently with resting spores of both this strain of $B$. megatherium and a laboratory strain of $B$. subtilis, that heating at $60^{\circ}$ stimulates the excretion of an unidentified substance with a well-defined absorption maximum at $270 \mathrm{~m} \mu$. This substance is present in the resting spore, and is excreted in much larger amounts during germination. Its identity and significance are being further investigated.

It is surprising that none of the reagents tested, with the single exception of oxine, inhibited germination in glucose. It has not been proved, however, that these substances enter the resting spore. The failure of the latter to take up dyes suggests that its permeability to other substances may also be relatively low.

The experimental data suggest that, in the presence of certain stimulatory substances, the spore will germinate under conditions which are totally unsuitable for growth, and which, in fact, do not permit the vulnerable germinated form to survive. The impression has been formed in the present study that the germination process is not directly reversible: i.e. if the spore germinates under conditions unfavourable for growth, it cannot revert immediately to its resistant form. It is suggested that the sporulation process requires energy; this is released in some way during germination and must be built up again by a growth phase before the cell, or its daughter cells, can revert to a spore form.

I wish to thank Dr D. W. Henderson for advice and criticism and Miss N. Harris for the photomicrographs. Permission to publish has been granted by the Chief Scientist, Ministry of Supply.

\section{REFERENCES}

Bordet, H. \& Renaux, E. (1930). L'influence du calcium sur l'évolution des cultures de charbon. Ann. Inst. Pasteur, 45, 1.

Emerson, M. E. (1948). Chemical activation of ascospore germination in Neurospora crassa. J. Bact. 55, 327.

Gladstone, G. P. \& Findes, P. (1940). A simple culture medium for general use without meat extract or peptone. Brit. J. exp. Path. 21, 161.

GodDARD, D. R. (1939). The reversible heat activation of respiration in Neurospora. Cold Spr. Harb. Sym. quant. Biol. 7, 362.

HILls, G. M. (1949a). Chemical factors in the germination of spore-bearing aerobes. The effect of amino-acids on the germination of Bacillus anthracis, with some observations on the relation of optical form to biological activity. Biochem. J. 45, 363.

HruLs, G. M. (1949 $b)$. Chemical factors in the germination of spore-bearing aerobes. The effect of yeast extract on the germination of Bacillus anthracis and its replacement by adenosine. Biochem. $J .45,353$.

Hruss, G. M. (1950). Chemical factors in the germination of spore-bearing aerobes: observations on the influence of species, strain, and conditions of growth. J. gen. Microbiol. 4, 38. 
KNAYSI, G. (1945a). A study of some environmental factors which control endospore formation by a strain of Bacillus mycoides. J. Bact. 49, 473.

KNaYSI, G. $(1945 b)$. Investigation of the existence and nature of reserve material in the endospore of a strain of Bacillus mycoides by an indirect method. J. Bact. 49,617 .

Powell, J. F. (1950). Factors affecting the germination of thick suspensions of Bacillus subtilis spores in L-alanine solution. J. gen. Microbiol. 4, 330.

TARR, H. L. A. (1933). Some observations on the respiratory catalysts present in spores and vegetative cells of certain aerobic bacilli. Biochem. J. 27, 136.

\section{EXPLANATION OF PLATE 1}

Fig. 1. Sporulation after 7 days on $\mathrm{CCY}$ agar at $35^{\circ}$.

Fig. 2. Washed suspension from Tarr medium showing one densely staining non-viable spore.

Fig. 3. Spore suspension from Tarr medium after incubation in $5 \mathrm{~mm}$. glucose and 33 mm. phosphate for $20 \mathrm{~min}$. at $35^{\circ}$.

Fig. 4. Sporulation after $24 \mathrm{hr}$. on Tarr medium at $35^{\circ}$.

Fig. 5. Sporulation after $24 \mathrm{hr}$. on Tarr medium $+25 \mathrm{~mm}$. glucose at $35^{\circ}$.

Magnification $\times 1700$.

(Received 19 April 1951) 
Journal of General Microbiology, Vol. 5, No. 5

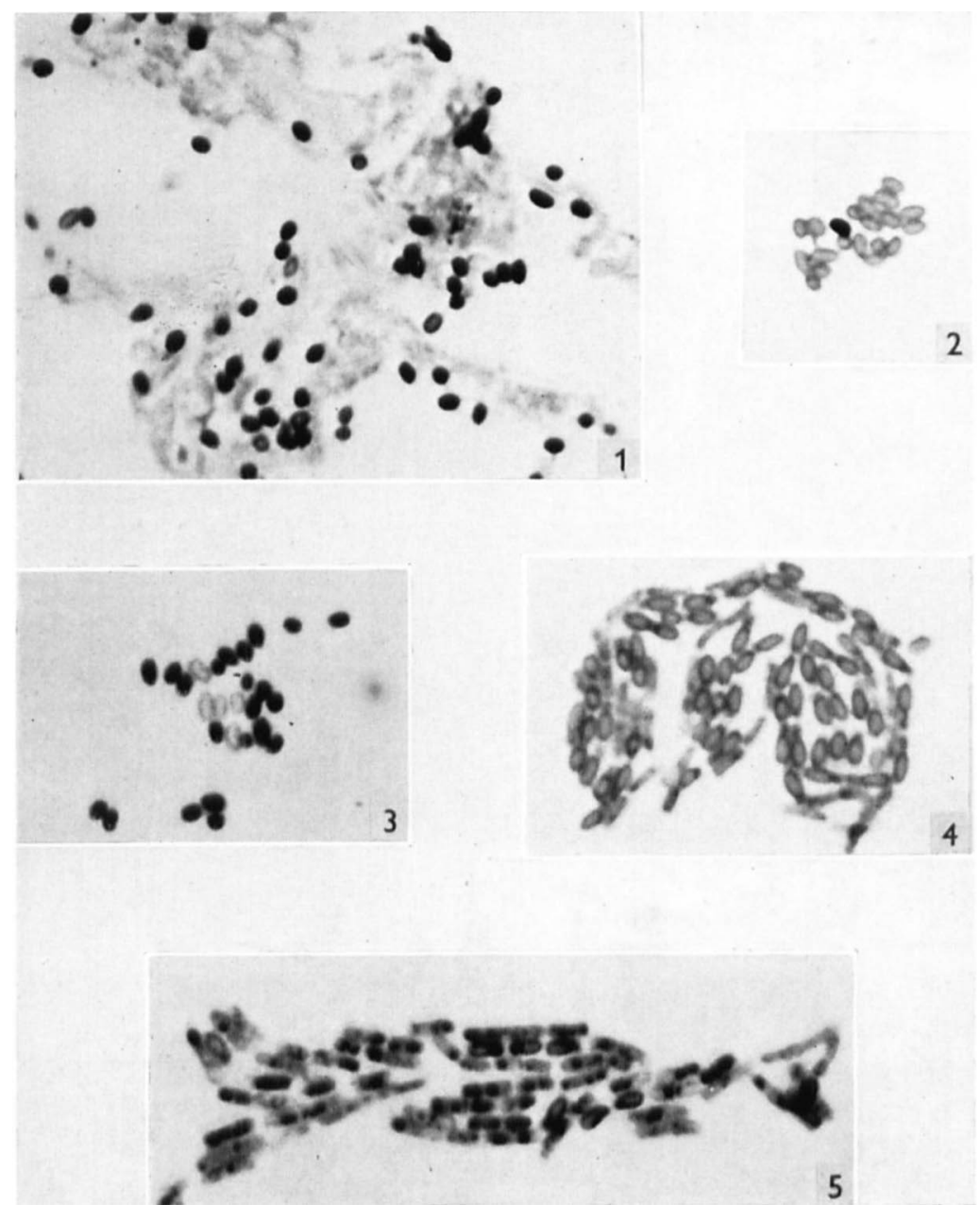

Figs. 1-5

J. F. Powell-The sporulation and germination of B. Megatherium. Prate 1 